\title{
Development of a reaction cell for in-situ/operando studies of surface of a catalyst under a reaction condition and during catalysis
}

Luan Nguyen, and Franklin (Feng) Tao

Citation: Review of Scientific Instruments 87, 064101 (2016); doi: 10.1063/1.4946877

View online: https://doi.org/10.1063/1.4946877

View Table of Contents: http://aip.scitation.org/toc/rsi/87/6

Published by the American Institute of Physics

\section{Articles you may be interested in}

A differentially pumped electrostatic lens system for photoemission studies in the millibar range

Review of Scientific Instruments 73, 3872 (2002); 10.1063/1.1512336

Design of a new reactor-like high temperature near ambient pressure scanning tunneling microscope for catalysis studies

Review of Scientific Instruments 84, 034101 (2013); 10.1063/1.4792673

Atmospheric pressure X-ray photoelectron spectroscopy apparatus: Bridging the pressure gap

Review of Scientific Instruments 87, 053121 (2016); 10.1063/1.4951724

A lab-based ambient pressure x-ray photoelectron spectrometer with exchangeable analysis chambers Review of Scientific Instruments 86, 085113 (2015); 10.1063/1.4928498

Laboratory-based high pressure X-ray photoelectron spectroscopy: A novel and flexible reaction cell approach

Review of Scientific Instruments 88, 033102 (2017); 10.1063/1.4975096

A new scanning tunneling microscope reactor used for high-pressure and high-temperature catalysis studies Review of Scientific Instruments 79, 084101 (2008); 10.1063/1.2960569

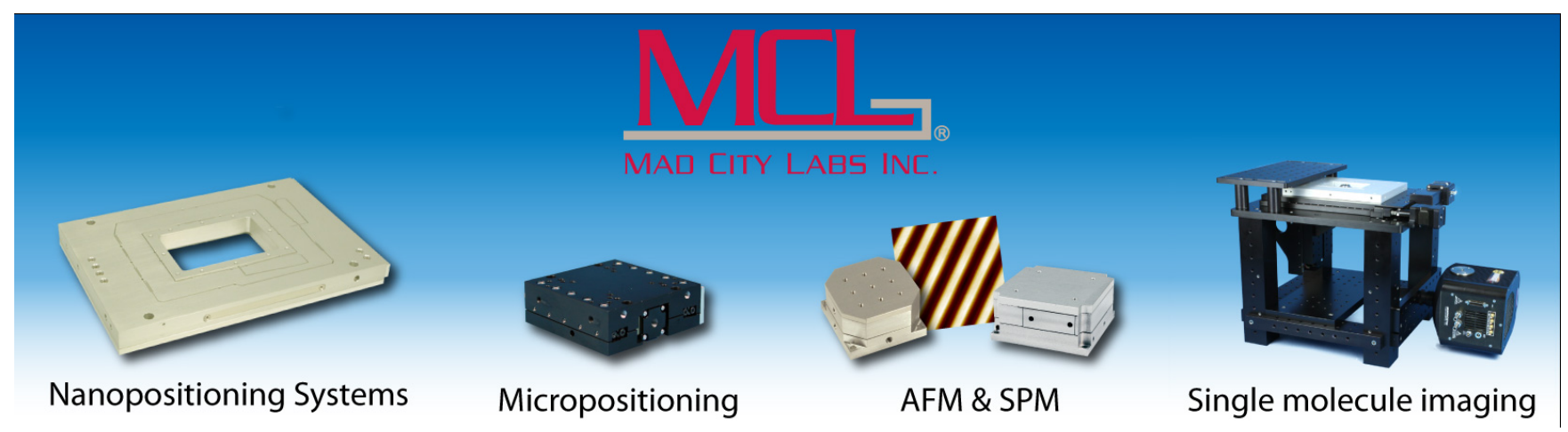




\title{
Development of a reaction cell for in-situ/operando studies of surface of a catalyst under a reaction condition and during catalysis
}

\author{
Luan Nguyen ${ }^{1,2}$ and Franklin (Feng) Tao ${ }^{1,2, a)}$ \\ ${ }^{1}$ Department of Chemistry and Biochemistry, University of Notre Dame, Notre Dame, Indiana 46556, USA \\ ${ }^{2}$ Department of Chemical and Petroleum Engineering, University of Kansas, Lawrence, Kansas 66045, USA
}

(Received 28 November 2015; accepted 2 April 2016; published online 7 June 2016)

\begin{abstract}
Tracking surface chemistry of a catalyst during catalysis is significant for fundamental understanding of catalytic performance of the catalyst since it allows for establishing an intrinsic correlation between surface chemistry of a catalyst at its working status and its corresponding catalytic performance. Ambient pressure X-ray photoelectron spectroscopy can be used for in-situ studies of surfaces of different materials or devices in a gas. To simulate the gaseous environment of a catalyst in a fixed-bed a flowing gaseous environment of reactants around the catalyst is necessary. Here, we report the development of a new flowing reaction cell for simulating in-situ study of a catalyst surface under a reaction condition in gas of one reactant or during catalysis in a mixture of reactants of a catalytic reaction. The homemade reaction cell is installed in a high vacuum (HV) or ultrahigh vacuum (UHV) environment of a chamber. The flowing gas in the reaction cell is separated from the HV or UHV environment through well sealings at three interfaces between the reaction cell and X-ray window, sample door and aperture of front cone of an energy analyzer. Catalyst in the cell is heated through infrared laser beam introduced through a fiber optics interfaced with the reaction cell through a homemade feedthrough. The highly localized heating on the sample holder and Au-passivated internal surface of the reaction cell effectively minimizes any unwanted reactions potentially catalyzed by the reaction cell. The incorporated laser heating allows a fast heating and a high thermal stability of the sample at a high temperature. With this cell, a catalyst at $800^{\circ} \mathrm{C}$ in a flowing gas can be tracked readily. Published by AIP Publishing. [http://dx.doi.org/10.1063/1.4946877]
\end{abstract}

\section{INTRODUCTION}

X-ray photoelectron spectroscopy (XPS) has been a valuable characterization technique in heterogeneous catalysis in the last three decades. ${ }^{1-3}$ Compared to other techniques, XPS has its unique functions. For instance, it identifies elements, measures surface composition, and analyzes the chemical state of atoms through measuring chemical shifts of a sub-shell energy level. ${ }^{1-3}$ The sampling depth of XPS technique is determined by the kinetic energies of the excited photoelectrons, which are typically in the range of 100 $\mathrm{eV}-1400 \mathrm{eV}$ if $\mathrm{Al} \mathrm{K} \alpha$ is used. Photoelectrons with these kinetic energies have inelastic mean free paths of about 5-12 $\AA$ when they travel through a condensed matter. ${ }^{4}$ This short mean free path makes XPS a surface-sensitive characterization technique. However, since photoelectrons are significantly scattered by molecules in gas phase when they travel through, the sample must remain in a high vacuum (HV) environment to allow for an effective collection of photoelectrons generated from the surface of the sample if a conventional vacuum XPS is used.

In terms of heterogeneous catalysis in a gaseous phase, pressure and temperature are two important factors, which significantly impact the formation of an active phase of a catalyst and its catalytic performance. ${ }^{5,6}$ As the contribution

\footnotetext{
a) Author to whom correspondence should be addressed. Electronic mail: franklin.tao.2011@gmail.com
}

of temperature or/and pressure-dependent entropy could restructure the catalyst surface, the chemistry and structure of an active catalyst surface in a reactant gas cannot be simply extrapolated from the surface chemistry and structure identified in ultrahigh vacuum (UHV) condition. ${ }^{7-12}$ From this point of view, tracking surface chemistry and structure of the catalyst in a gas environment of one or more reactants at a specific pressure or/and temperature is necessary. Unfortunately, in most cases, an electron gun of X-ray source and an electrostatic lens of energy analyzer must be performed in a high vacuum condition. ${ }^{4}$ Thus, gas cannot be introduced to a regular XPS chamber. Examination of a catalyst surface in a gas phase is impossible by a regular vacuum XPS. In terms of an in-situ characterization of a catalyst surface in a gas phase, a common approach is the creation of a local gaseous environment containing the functional materials or devices of interest such as a catalyst, a fuel cell, or Li-battery.

A straightforward method to create a local high pressure environment of a reactant gas is to directly fill a UHV chamber with a reactant gas (Figure 1(a)). This method allows for studies of a sample in a gas phase without any complicated instrumentation. In addition, this method was used in tracking surface in a static gaseous environment. Since the setup of this method is not complicated, one can employ this method without much instrumentation. This method does not involve any sealing of gas in a small vessel and engagement of a small gaseous cell to the energy analyzer. It is widely used in in-situ studies of devices or energy conversion such as model fuel cell 


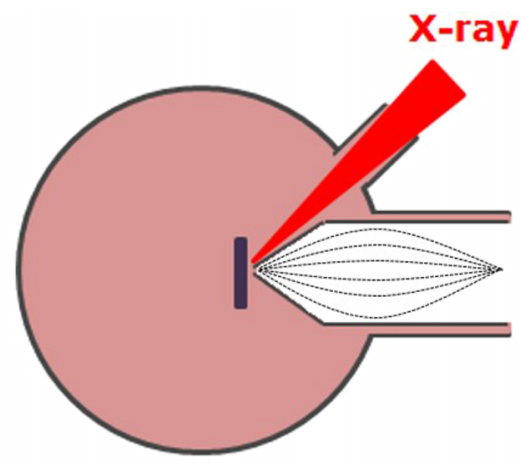

(a)

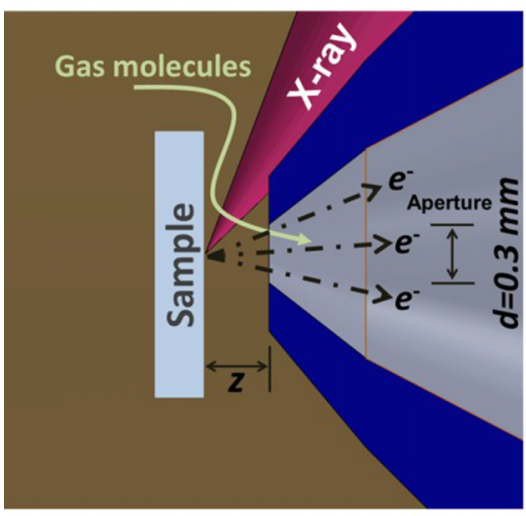

(c)

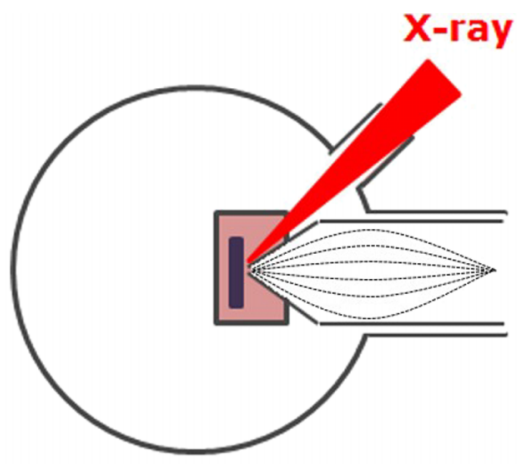

(b)

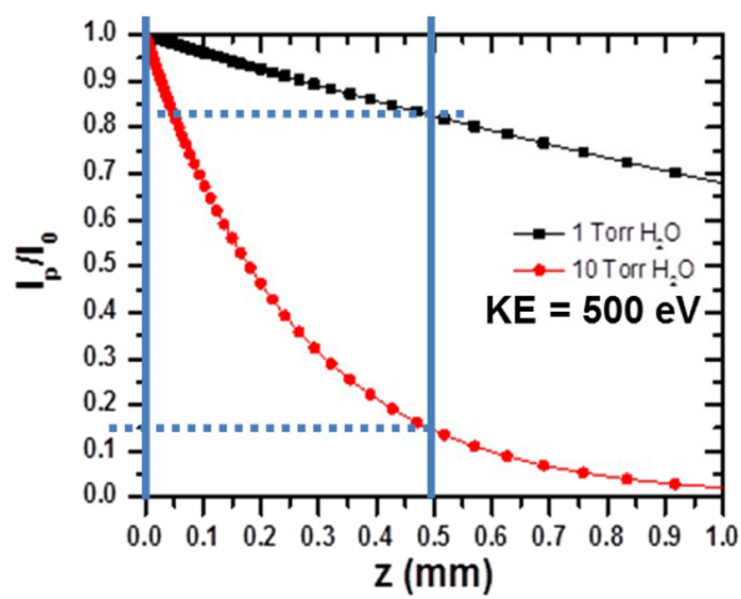

(d)

FIG. 1. Schematics showing instrumentation modes of AP-XPS setups and the configuration of sample and aperture in a gas phase. (a) Model of filling gas to a UHV chamber; the circle schematically shows a cylinder chamber. (b) Integration of a reaction cell (filling with small amount of gas) to a UHV chamber; the box filling with pink schematically shows in a reaction cell. (c) Schematic showing the X-ray beam, sample surface, and aperture. (d) Plot of collection rate $\left(\mathrm{I}_{\mathrm{p}} / \mathrm{I}_{\mathrm{O}}\right)$ as a function of sample-aperture distance $(\mathrm{mm})$, $\mathrm{z}$ after photoelectrons of $500 \mathrm{eV}$ travel through a $\mathrm{H}_{2} \mathrm{O}$ vapor with a pressure at 1 Torr and 10 Torr. Reproduced with permission from Y. Tang, L. Nguyen, Y. Li, N. Wang, and F. Tao, "Surface of a catalyst in a gas phase," Curr. Opinion. Chem. Eng. 12, 52-61 (2016). Copyright 2016 Elsevier, Inc.

and model battery. ${ }^{12-16}$ Typically, the flow rate is in the range of $0.01-0.1 \mathrm{ml} / \mathrm{min}$. Parallel to the method of filling gas to a UHV chamber, another method of creating a local high pressure environment in UHV was used in instrumentation of in-situ studies of catalysts; ${ }^{17-22}$ in this method, a reaction cell can be integrated at the crossing point of directions of X-ray beam and trajectory of elections in energy analyzer (Figure 1(b)). In either of the two methods, a key parameter for a successful in-situ study of surface of a sample in a gas phase using XPS is the correlation among aperture size, sample-aperture distance, and pressure of gas above the sample surface. This correlation is schematically shown in Figure 1(c).

The sample-aperture distance $(\mathrm{z})$ is the travel distance of photoelectrons. $I_{o}$ and $I_{p}$ are intensities of photoelectrons excited from surface of a sample in UHV and collected in gas phase with a pressure $p$ at a distance of $z$ from sample surface. As shown in the equation, $\frac{I_{p}}{I_{o}}\left(E_{K}, p\right)=e^{\frac{-z \sigma_{E_{K}} p}{\kappa T}}$, the fraction of the collected photoelectrons $\left(\frac{I_{p}}{I_{0}}\right)$ with a particular kinetic energy $\left(E_{K}\right)$, exponentially decreases along the increases of sample-aperture distance in terms of the travel distance of photoelectrons in a gas phase and the pressure of gas $(p)$ they travel through. ${ }^{4}$ In this case, $k$ is the Boltzmann constant,
$T$ is the temperature of gas, and $\sigma$ is the electron scattering cross section for a particular gas specie. Figure 1(d) plots this exponential decay of collection rate $\left(\frac{I_{p}}{I_{o}}\right)$ of photoelectrons of $500 \mathrm{~V}$ in 1 Torr $\mathrm{H}_{2} \mathrm{O}$ and 10 Torr $\mathrm{H}_{2} \mathrm{O}$ as a function of the sample-aperture distance. Definitely, the decay is much faster at a higher pressure. Based on this exponential dependence, a shorter distance, $\mathrm{z}$, at the same interested pressure $p$ allows for collecting more photoelectrons. However, to make the gas pressure on the sample surface $\left(p^{\prime}\right)$ to be $90 \%$ of the gas pressure $\left(p_{o}\right)$ measured on the reaction cell (for the cell mode in Figure 1(b)) or the wall of chamber (for the chamber mode in Figure 1(a)), the sample-aperture distance should be typically at a distance equal or larger than the diameter of aperture $(d)(d \leq z)$. To collect $37 \%$ or more of photoelectrons generated from surface in UHV $\left(I_{o}\right)$ typically, the sample-aperture distance is remained at a distance of the mean free path $(\lambda)$ of photoelectrons or smaller $(z \leq \lambda)$ in gas at the interested pressure $(p)$. The mean free path $\lambda$ is determined by the pressure of gas environment around the catalyst, the molecular weight of gas molecules, and the kinetic energy of photoelectrons. Thus, the interested pressure of the gas phase of reactant gas(es) and energy of photoelectrons, 
$E_{K}$ decides the mean free path $\left(\lambda_{p}\right)$. The $\lambda_{p}$ limits the range of sample-aperture distance $\left(z \leq \lambda_{p}\right)$, which further limits the size of aperture interfaced at the gas phase of sample and vacuum of the energy analyzer $\left(d \leq z \leq \lambda_{p}\right)$. Unfortunately, the smaller diameter of the aperture gives much smaller collection rate (number of photoelectrons per second), which is approximately proportional to area of the aperture, $A=\frac{\pi d^{2}}{4}$. Thus, essentially, the pressure limits the collection area of photoelectrons. At a higher pressure, the aperture has to be smaller, resulting in a smaller collection rate of photoelectrons. To collect enough photoelectrons at aperture for a reasonable single/noise ratio, a higher flux density of X-ray beam is necessary for $i n$-situ/operando studies of surface of catalyst in a gas at a higher pressure.

Compared to the characterization of surface of a material or device in a gas phase, tracking the surface of a catalyst during catalysis requires the mixture of reactant gases to flow through the catalyst. Typically, a flow rate of gas in a chamber with a volume of 301 is only $0.01-0.1 \mathrm{ml} / \mathrm{min}$ when the gas is pumped by an aperture of front cone of the pre-lens through two turbo pumps with a pumping rate of $380 \mathrm{l} / \mathrm{min}$. In almost static gas environment, the formed product molecules are likely accumulated in the region near to the catalyst surface; these product molecules likely re-adsorb on the catalyst surface. A surface in such an almost static environment could be quite different from that in a flowing gas phase of reactants as the former typically is not under a kinetic control condition.

Facing to this expected diffusion limit resulting from the extremely low flow rate of reactant gases in a chamber mode, use of a reaction cell could be necessary. Flow rate of a reaction cell is about $1-10 \mathrm{ml} / \mathrm{min}$ under the same pumping capability of the two pumps installed at pre-lens stage since the volume of a reaction cell is typically only $20-30 \mathrm{ml}$ or smaller, much smaller than a UHV chamber (20-30 1). In this paper, a design of a new reaction cell is reported. The instrumentation and its features are the focus of this article.

\section{II. "IDEAL" CHARACTERIZATION OF SURFACE OF A CATALYST IN A FIXED-BED FLOW REACTOR DURING CATALYSIS USING AMBIENT PRESSURE XPS (AP-XPS)}

Catalytic performances of industrial catalysts are commonly tested using fixed-bed flow reactors. In this setup, small amount of catalyst power $(\sim 10-100 \mathrm{mg})$ is loaded into a small reactor tube and sandwiched between two clogs of quartz wool. Reactant gases flow into the reactor tube and through the catalyst bed. Reaction products at the downstream are analyzed typically by a gas chromatograph. In this case, an ideal in-situ characterization would be to characterize the catalyst during working condition in the exact experimental setup mentioned above where the catalyst's catalytic performance is measured. An ideal integration of in-situ characterization using XPS to a fixed-bed flow reactor is to introduce $\mathrm{X}$-ray irradiation through a window to excite photoelectrons from surface of a catalyst loaded on a sample stage in a fixed-bed flow reactor and collect some of these

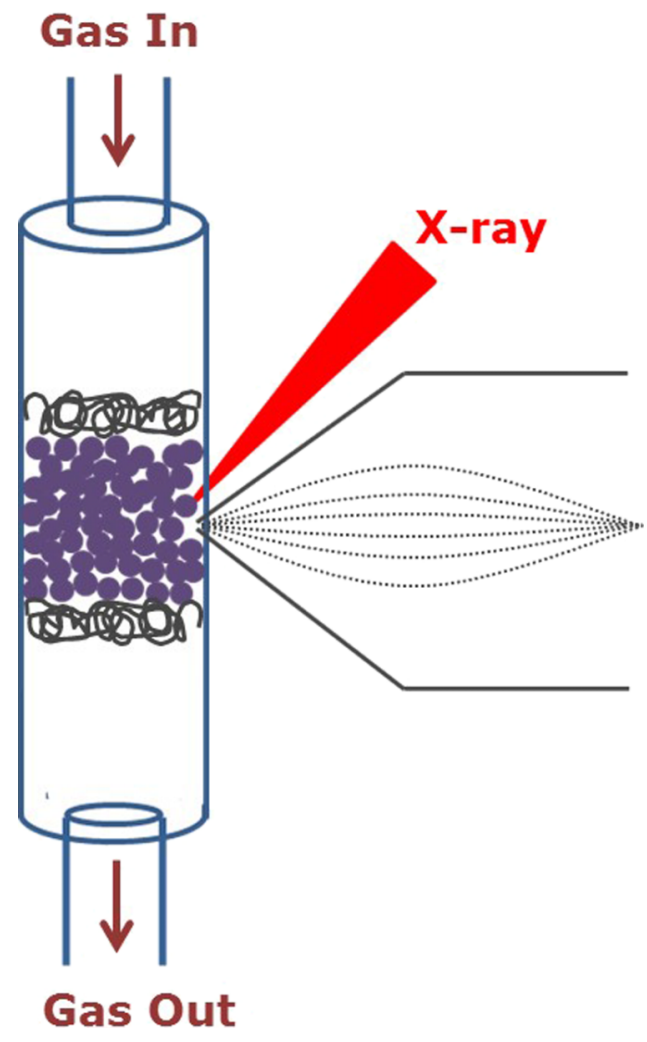

FIG. 2. Schematic showing an ideal characterization through integration of in-situ AP-XPS and a real fixed-bed flow reactor. The pink balls represent catalyst particles (20-60 mesh). Reproduced with permission from Y. Tang, L. Nguyen, Y. Li, N. Wang, and F. Tao, "Surface of a catalyst in a gas phase," Curr. Opinion. Chem. Eng. 12, 52-61 (2016). Copyright 2016 Elsevier, Inc.

photoelectrons through an aperture for surface analysis. Figure 2 is a schematic of such an ideal instrumentation. In this "ideal" characterization, the surface to be examined by AP-XPS is the authentic surface of catalyst particles loaded in a fixed-bed flow reactor, while a catalytic reaction is performed on the catalyst under a kinetics control regime. Instrumentation of such an ideal characterization needs a perfect integration of AP-XPS with a fixed-bed flow reactor. However, such an instrumentation posts un-overridden challenge to realize the perfect integration at this moment though we have started a similar design and will report in the near future. The main challenge is the lack of control of sample-aperture distance; the catalyst bed consists of loosely packed catalyst powder; these catalyst particles can be readily sucked into the aperture of AP-XPS (Figure 2), thus preventing photoelectrons from being collected through the aperture and damaging the differential pumping system of the pre-lens. Therefore, currently, direct integration of X-ray source and ambient pressure energy analyzer to a realistic fixed-bed flow reactor is definitely challenging. Incorporation of a reaction cell with $\mathrm{X}$-ray source and an ambient pressure energy analyzer is feasible. Integration of a mode reaction cell to synchrotron source was reported. ${ }^{22}$ Here, we developed a new reaction cell, which simulates the surface of a catalyst in a flowing gas environment of reactants. It was designed to integrate with monochromated $\mathrm{Al} \mathrm{K} \alpha \mathrm{X}$-ray source for in-situ studies of 
catalyst surface in a gas phase under reaction condition and during catalysis.

\section{INSTRUMENTATION AND FEATURES OF A NEW REACTION CELL}

\section{A. A brief description of the new reaction cell}

As schematic shown in Figure 1(b), the reaction cell must allow X-ray to irradiate a catalyst surface while a catalyst is remained in a gas environment of the reaction cell. Thus, typically a $\mathrm{Si}_{3} \mathrm{~N}_{4}$ window transparent for X-ray is installed. The transmission and alignment of $\mathrm{Si}_{3} \mathrm{~N}_{4}$ window will be discussed in Section III B. To safely remain gas pressure up to 1 bar in a reaction cell while the external environment of the reaction cell is at high vacuum, reactant gas must be sealed in the reaction cell with a minimal leaking. The sealing mechanism between the reaction cell and a front cone of ambient pressure energy analyzer as well as different window of the reaction cell will be discussed in Section III C. To install/retract a sample and locate a sample at the best position, a movable sample stage was installed. Particularly, the measurement and control of sampleaperture distance are crucial for a reproducible measurement of photoemission intensity; the control of sampleaperture distance and its accuracy will be discussed in Section III D. As thermal catalytic reactions are performed in a wide temperature range $\left(50-800{ }^{\circ} \mathrm{C}\right)$, heating capability is a critical function of a reaction cell; integration of laserheating to the reaction cell will be described in Section III E. In most cases, a reaction cell definitely should be maintained at a temperature close to room temperature while a catalyst loaded on the sample stage in the reaction cell is at a desired temperature; this is particularly important for a reaction cell made of stainless steel since the cell itself could be a catalyst for some reactions. To minimize heat dissipation from catalyst to the reaction cell, instrumentation for localizing sample heating is crucial; it will be discussed in Section III F. In addition, functions of the reaction cell will be discussed in Section III G.

\section{B. Transmission of X-ray photons}

Based on the correlation between pressure of reactant gases in a reaction cell and the size of aperture described in the Introduction and schematically shown in Figure 1(c), the aperture size is typically in the range of $0.3 \mathrm{~mm}$ for $10-25 \mathrm{Torr}$, $0.5 \mathrm{~mm}$ for $1-10$ Torr, and $0.7 \mathrm{~mm}$ for $\leq 1$ Torr. To collect more photoelectrons to achieve a better signal-to-noise ratio, high flux density of X-ray beam, defined to be the number of photons per area per second, is the key parameter. It typically needs to be $>5 \times 10^{11}$ photons/s in front of aperture when a $0.7 \mathrm{~mm}$ aperture is used and gas pressure is about 5 Torr. To have certain number of photons per second, a small beam spot with a higher flux density is a much better choice than a larger beam size with lower flux density since the collection area of photoelectrons in terms of the size of the aperture is typically $0.3-0.8 \mathrm{~mm}$ only (Figure $1(\mathrm{c})$ ). To generate an $\mathrm{X}$ ray beam with high flux density, typically a highly focused electron beam is necessary for impinging $\mathrm{Al}$ thin film deposited on substrate such as $\mathrm{Cu}$. This highly focused beam can excite $\mathrm{Al} \mathrm{K \alpha}$ with a high flux density at the level of $1 \times 10^{12}$ photons $\mathrm{mm}^{-2} \mathrm{~s}^{-1}$ or higher.

As shown in Figure 3, a misalignment could readily block a part or all of the X-ray beam. Therefore, high precision machining work must be employed when making the reaction cell and the analysis chamber. In addition, the convergence angle of the $\mathrm{X}$-ray source must be taken into account to ensure that the $\mathrm{Si}_{3} \mathrm{~N}_{4}$ window on the cell is large enough for the entire $\mathrm{X}$-ray beam to go through. The alignment of X-ray beam can be checked by placing an $\mathrm{X}$-ray sensitive luminescent material such as $\mathrm{ZnS}$ (Ag type 1330). To check if portion of the X-ray beam is blocked by the cell window, we used a Ag foil sample and monitor the $\mathrm{Ag} 3 \mathrm{~d}$ peak intensity when the sample is inside the cell versus without using the reaction cell. We confirmed that there was $10 \%$ decrease in $\mathrm{Ag} 3 \mathrm{~d}$ signal intensity when the Ag sample was inside the cell. However, this decrease in signal intensity is expected as a $100 \mathrm{~nm} \mathrm{Si}_{3} \mathrm{~N}_{4}$ film absorbs approximately $10 \%$ of X-ray radiation.

\section{Sealing reactant gas in reaction cell for maintaining the high vacuum environment of X-ray source and UHV chamber}

As mentioned above, the electron beam bombarding aluminum thin film must stay in a high vacuum and a surface cleaning process of a sample or vapor deposition of atoms or ions of a metal or oxide source can be only done in a UHV environment with a pressure lower than $1 \times 10^{-9}$ Torr. Thus, all sealings of the reaction cell are critical for maintaining a $\mathrm{HV}$ or UHV environment in the chamber. Three types of sealing were

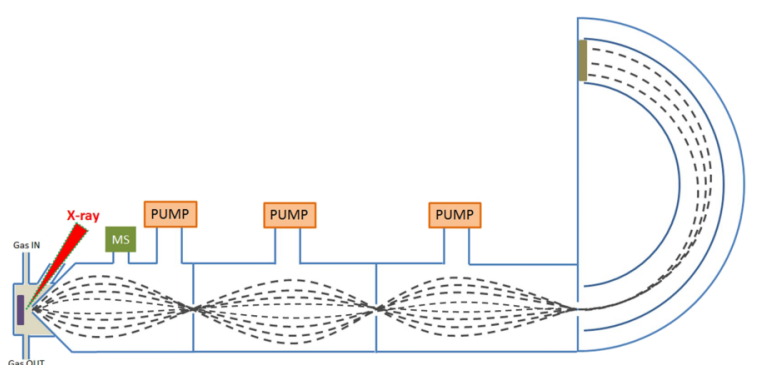

(a)

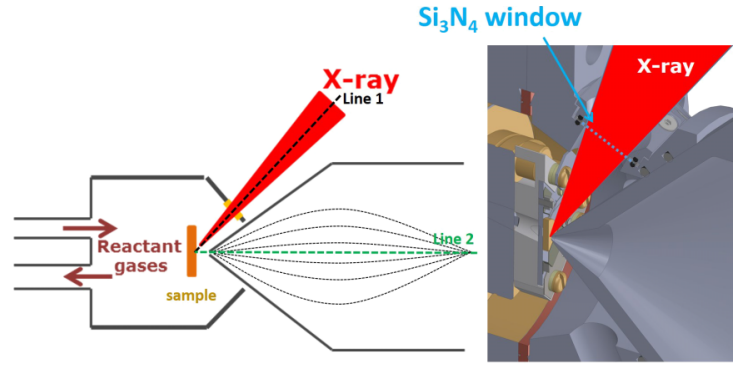

(b)

(c)

FIG. 3. Schematics showing alignment of the monochromatic x-ray beam, $\mathrm{Si}_{3} \mathrm{~N}_{4}$ window, sample surface, and aperture of the energy analyzer. (a) Alignment of the X-ray sample and the trajectory of photoelectrons. (b) Transmission of the entire X-ray beam through the well-aligned Si ${ }_{3} \mathrm{~N}_{4}$ window. (c) A perfect alignment between the $\mathrm{Si}_{3} \mathrm{~N}_{4}$ window and the x-ray source where no x-ray beam is blocked. 


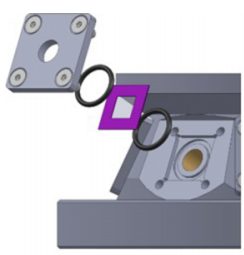

(a)

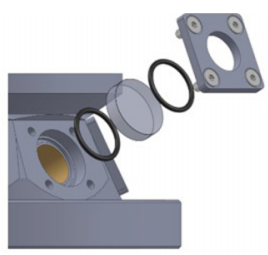

(b)

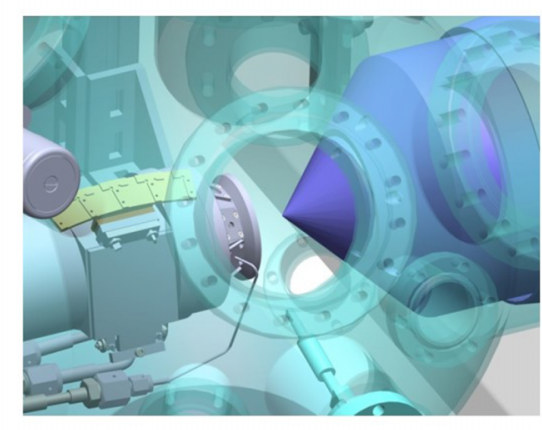

(e)

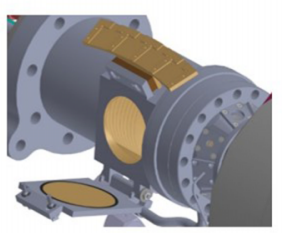

(c)

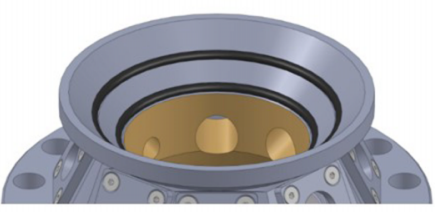

(d)

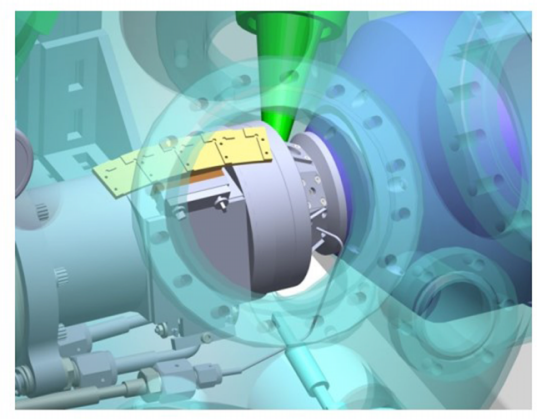

(f)

FIG. 4. Sealing mechanism for different interfaces with the UHV environment of chamber. (a) Sealing mechanism for X-ray $\mathrm{Si}_{3} \mathrm{~N}_{4}$ window; black circles are two identical O-ring anchored on two sides of a $\mathrm{Si}_{3} \mathrm{~N}_{4}$ window (the pink part). (b) Sealing mechanism of fused silica windows; the transparent disk is the window. (c) Sealing of the sample door of the reaction cell; the internal surface of the door was coated with Au for passivation of activity of the stainless steel. (d) Sealing of the cell neck through a perfect alignment between the female cell neck and the male front cone of the ambient pressure energy analyzer; the alignment does not need any locker; the alignment can be automatically optimized by applying a force from a linear manipulator. (e) Reaction cell retracted away from the front cone of the energy analyzer, respectively. (f) Reaction cell is well aligned and engaged to the front cone of the energy analyzer.

necessary. The silicon nitride (Figure 4(a)) or other fused silica windows (Figure 4(b)) are sealed through O-ring of Viton or metal wiring; the sample door is sealed with an O-ring of Viton (Figure 4(c)); the interface between the cell neck (Figure 4(d)) and aperture fixed on front cone of ambient pressure energy analyzer is sealed by a two level O-rings held in two grooves of cone of the cell neck. As shown in Figure 4(e), the cell neck has the exactly same aspect ratio as that of the front cone of ambient pressure energy analyzer; thus, a perfect engagement is expected as shown in Figure 4(f). This sealing mechanism does not require locking mechanism. Approaching and engagement through a XYZ stage manipulator can provide a nice sealing as in the testing results shown in Figure 5(c). As shown in Figure 6(a), the axis of the reaction cell (marked with a red line in Figure 6(a)) is obviously offset from the trajectory of electrons in the energy analyzer (marked with a white line in Figure 6(a)) by $3^{\circ}$. To correct this offset commonly happened, the reaction cell was assembled on a supporting scaffold of a $\mathrm{X}-\mathrm{Y}-\mathrm{Z}$ manipulator. The flexibility of the lateral position of the reaction cell through a homemade connecting part between cell and the manipulator makes the cell neck automatically adjust itself to reach the best fitting to the front cone without any external force (Figure 6(b)). This design was inspired by the auto-correction of a tip holder with a convex shape when it is placed to the bowl-like receiver of tip holder with a concave shape in the design of a high pressure STM $;{ }^{19}$ in our previous design of a high pressure STM, the concave tip-receiver allows the convex tip holder automatically correct its orientation to reach an optimum alignment.

The sealing of the reaction cell at the three types of interfaces was tested after the reaction cell well aligned to the front cone of ambient pressure energy analyzer and the sample door of the reaction cell was closed. Then, nitrogen gas was introduced to the sealed reaction cell. Pressures of nitrogen in the reaction cell (Figure 5(a)) and in UHV chamber (Figure 5(b)) were recorded simultaneously. All pressures shown in Figure 5 were measured after the gas was introduced and then maintained in the cell for $10 \mathrm{~min}$. As shown in Figure 5(c), the base pressure $\left(1.4 \times 10^{-7}\right.$ Torr $)$ only increased by $2.0 \times 10^{-7}$ Torr when the pressure of gas in the reaction cell was increased to 760 Torr. It suggested the sealing of the $\mathrm{Si}_{3} \mathrm{~N}_{4}$ window and others can resist pressure of $1 \mathrm{~atm}$. In other words, the three interfaces only give a leaking of $2.0 \times 10^{-7}$ Torr even if the pressure in the cell is $1 \mathrm{~atm}$. The UHV chamber hosting the reaction cell is used for sample cleaning and pretreatments. To perform fundamental studies of vacuum-based surface sciences, a pressure lower than $1 \times 10^{-9}$ Torr is necessary for the hosting chamber. The hosting chamber has a base pressure of $8 \times 10^{-10}$ Torr when $\mathrm{N}_{2}$ was introduced progressively up to 10 Torr $\mathrm{N}_{2}$. As shown in Figure 5(d), the pressure of UHV chamber remained at $8 \times 10^{-10}$ Torr when the reaction cell was filled with 10 Torr flowing $\mathrm{N}_{2}$. It further suggests that the sealing of this reaction cell is good enough to maintain a UHV environment for surface science studies of a sample in UHV chamber.

\section{Measurement and control of sample-aperture distance}

As the sample-aperture distance is the key for a successful collection of photoelectrons generated from a catalyst surface in a gas phase, control of the sample-aperture distance is 


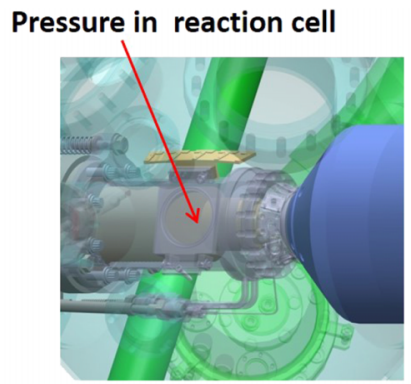

(a)

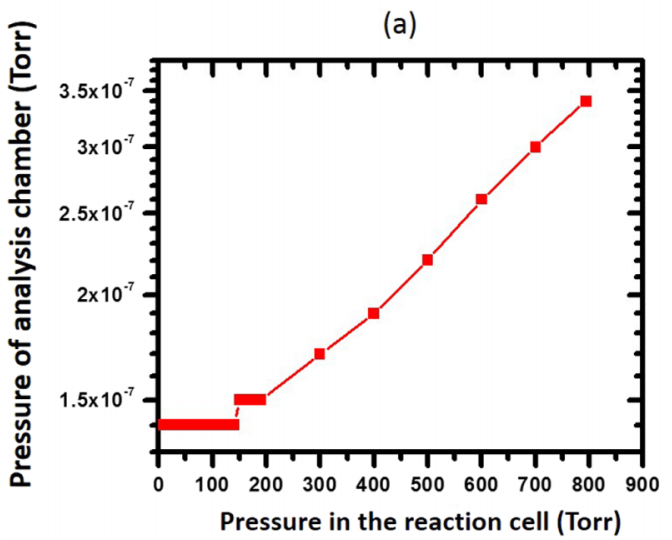

(c)

\section{Pressure in UHV chamber}

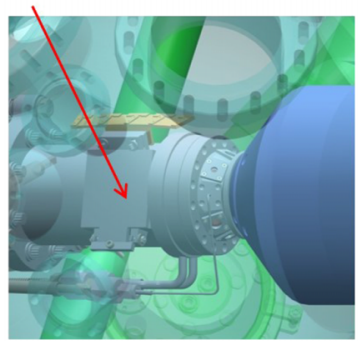

(b)

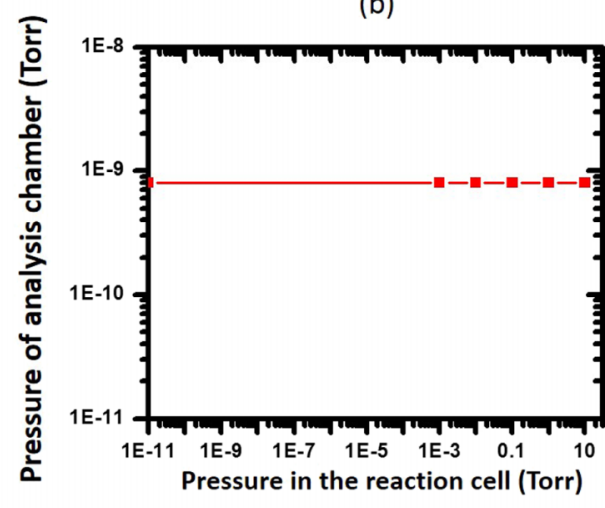

(d)

FIG. 5. Sealing performance of the in-situ reaction cell. (a) Location of the pressures measured in the reaction cell. (b) Location of the pressure measured in UHV chamber. (c) Plot of the measured pressures in UHV as a function of pressures of the introduced $\mathrm{N}_{2}$ up to 800 Torr in the cell; the base pressure of the UHV chamber is $1.4 \times 10^{-7}$ Torr before any $\mathrm{N}_{2}$ was introduced to the reaction cell. (d) Plot of the measured pressures in the UHV chamber as a function of pressures of $\mathrm{N}_{2}$ in the reaction cell up to 10 Torr; the base pressure is $8 \times 10^{-10}$ Torr before any $\mathrm{N}_{2}$ was introduced to the reaction cell.

crucial. As the sample-aperture distance is typically in the range of the mean free path, a change of sampler-aperture distance by $0.10 \mathrm{~mm}$ can increase or decrease the number of photoelectrons collectable at aperture by $\sim 10 \%$ or even more for $500 \mathrm{~V}$ electron in 10 Torr $\mathrm{H}_{2} \mathrm{O}$. Thus, an accurate control of the sample-aperture distance is key when absolute intensities of photoemission peaks at different experimental conditions are necessarily compared in some analyses. For precisely controlling the sample-aperture distance, a linear manipulator with encoded motor capable of providing accuracy of $2.5 \mu \mathrm{m}$

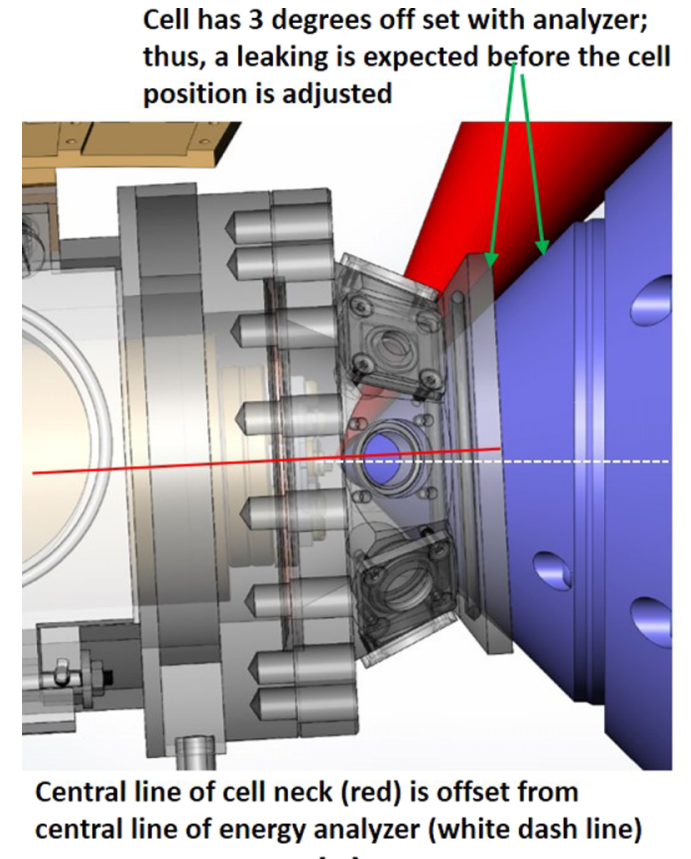

(a)

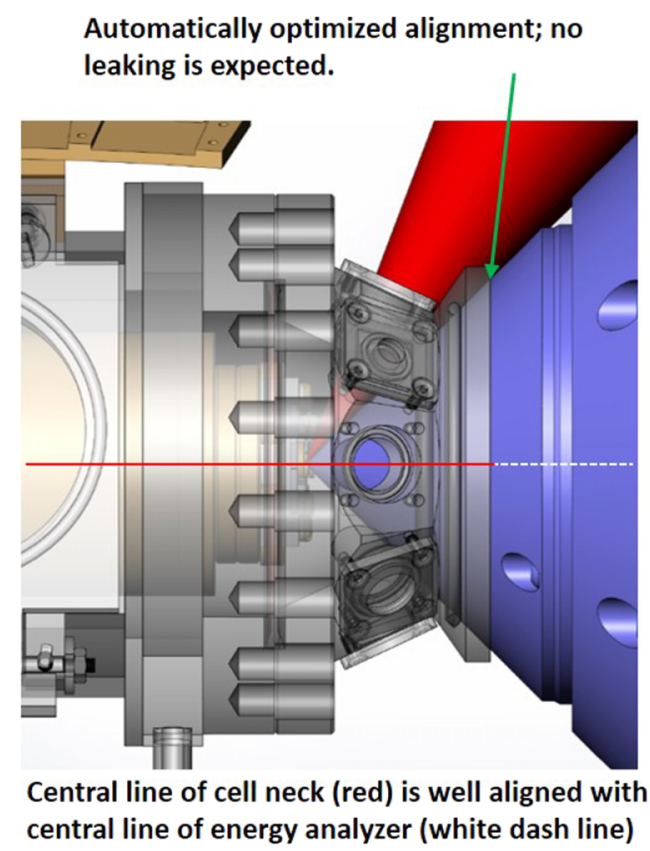

(b)

FIG. 6. Important alignment of X-ray beam and trajectory of photoelectron and mechanism of sealing of reaction cell at the interface of cell neck and aperture/front cone of ambient pressure energy analyzer. (a) Misaligned cell and front cone of energy analyzer. (b) Perfectly aligned cell and energy analyzer. 


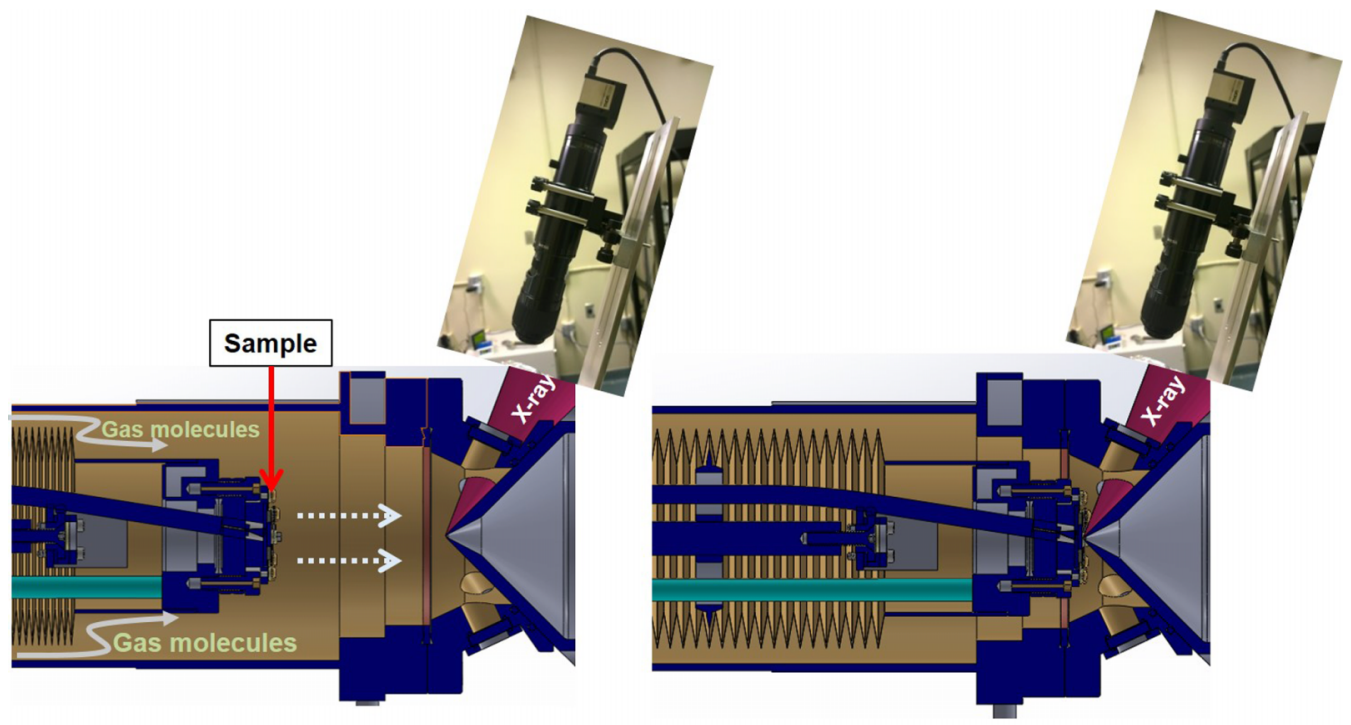

(a)

(b)

FIG. 7. Schematic showing the process of approaching the sample to the front cone aperture of an energy analyzer. A CCD camera is used to monitor the distance between the sample and the aperture to make sure a reproducible sample-aperture distance can be achieved. (a) Sample is away from the aperture. (b) Sample is close to the aperture with a distance of $0.5 \mathrm{~mm}$.

per step was installed on this system. The change of distance can be reproducibly measured and controlled with software installed on the computer of the system.

Other than the accurate control of the distance, visualization of sample surface and aperture and their surroundings is important for a safe and repeatable experiment. As shown in Figure 7, a high-resolution video camera was installed for checking the relative position of sample to the aperture fixed on the energy analyzer and measuring sample-aperture distance. It can visualize surface of a catalyst and the aperture on computer screen of the work station. As shown in Figure 8(d), both the sample surface and aperture can be clearly observed although the sample-aperture distance was only $0.3 \mathrm{~mm}$. The $0.3 \mathrm{~mm}$ can be shown on the screen as large as $5 \mathrm{~cm}$ or even larger. The movement of every 5 steps $(12.5 \mu \mathrm{m})$ can be magnified to $2000 \mu \mathrm{m}$ on the screen. In other words, a subtle change of sample-aperture distance by $12.5 \mu \mathrm{m}$ is visible on the computer screen through the magnification of the video camera. Thus, the video camera significantly helps to measure and control subtle changes of the sample-aperture distance and check the areas around a sample and tracking the aperture during movement of a sample and doing experiments.

\section{E. Integration of heating of infrared laser beam to reaction cell}

Heating through (1) bombardment of electron beam or (2) electric current heating in terms of resistive heating is widely used in heating a sample in UHV to a high temperature since the HV and UHV allow for bombardment of electron beam or application of an electrical potential to a sample directly. Unfortunately, electron-beam heating cannot be simply applied to heat a sample in gas environment with a pressure higher than $10^{-6}$ Torr due to severe scattering of electrons by molecules in the gas phase, shorten lifetime of heating filament, and generation of dissociated gaseous species. A resistive heating of a sample holder could be applicable but not ideal; an obvious side effect of resistive heating of a sample in a gas phase is a potential charging to the gas phase around the sample.

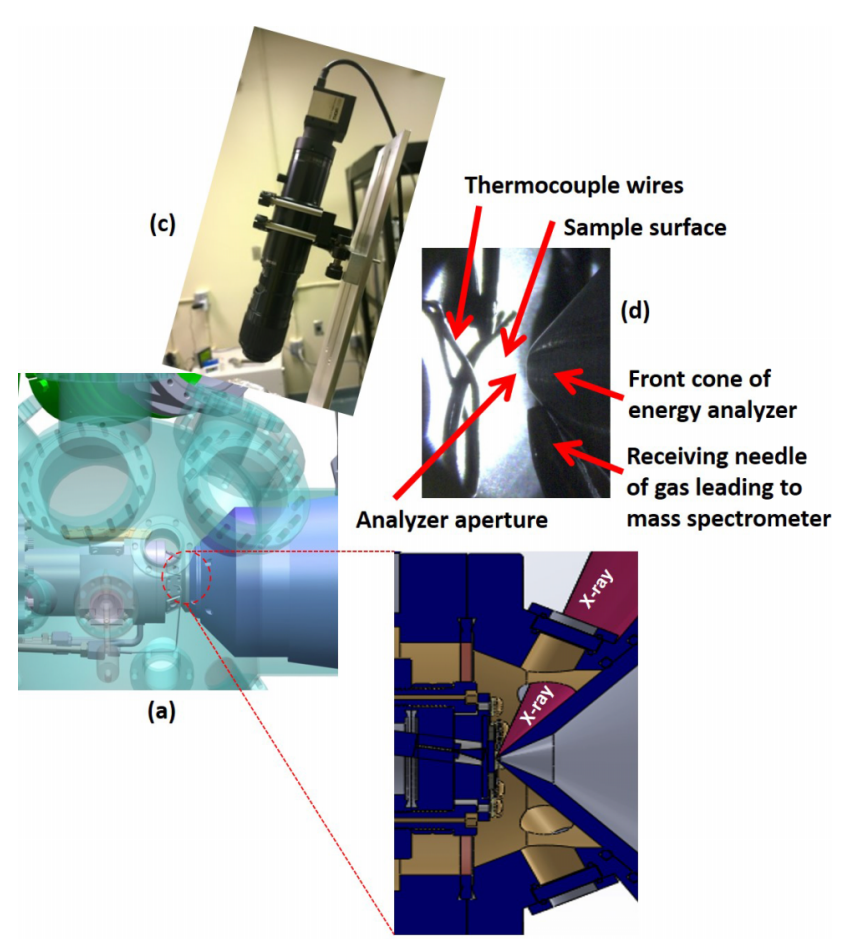

(b)

FIG. 8. Schematic and photo of distance between the sample and the front cone aperture. ((a) and (b)) Status of sample and aperture when the neck of the reaction cell matches the font cone. (c) Video camera to visualize the sample and aperture through a $4.5^{\prime \prime}$ flange window of UHV chamber and a glass window of the reaction cell. (d) Photo of the screen on a computer showing the magnified region of sample and aperture and their surroundings. 


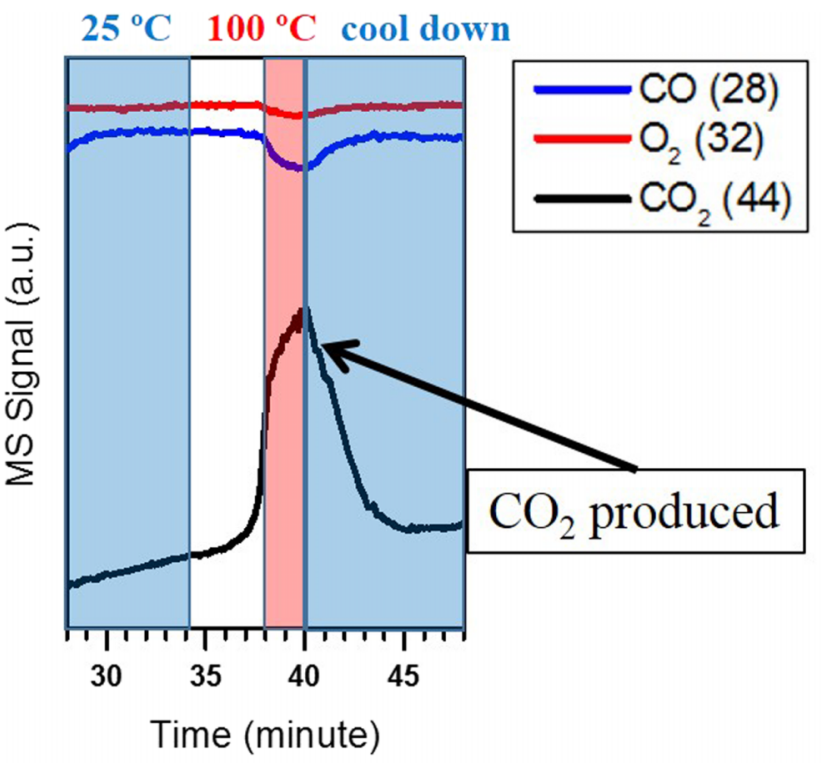

(a)

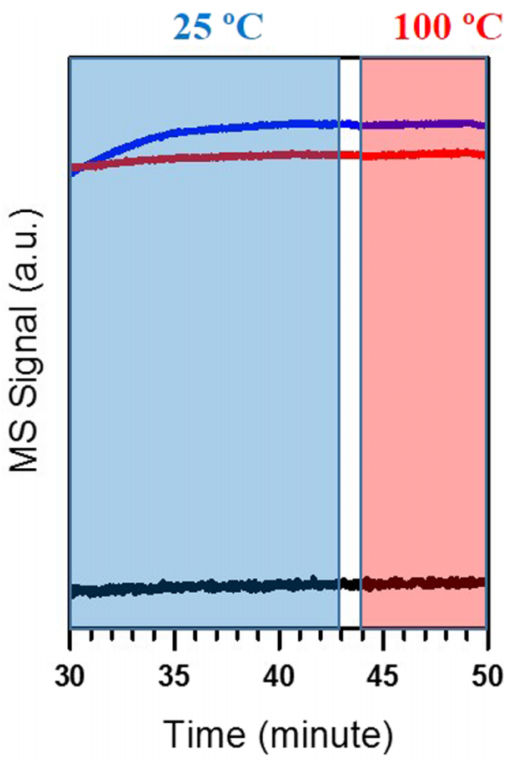

(b)

FIG. 9. Mass spectrometer data from two type of reaction cells with different sample heating mechanisms. Mixture of 0.1 Torr $\mathrm{CO}$ and $\mathrm{O}_{2}$ was introduced into the cells. The sample holder was a blank tantalum sheet without any catalyst. In (a), sample holder was heated indirectly through the sample stage, which was conductively heated through the external surface of the reaction cell bombarded by electron beams in $\mathrm{UHV}_{\mathrm{H}} \mathrm{CO}$ and $\mathrm{O}_{2}$ were being flown through the reaction cell. Production of $\mathrm{CO}_{2}$ was observed at $100{ }^{\circ} \mathrm{C}$ even there was no catalyst present. In (b), the sample was heated directly through IR laser radiation with the reaction cell developed here. No formation of $\mathrm{CO}_{2}$ was observed at $100^{\circ} \mathrm{C}$ while both $\mathrm{CO}$ and $\mathrm{O}_{2}$ were being flown through the reaction cell.

A conductive heating of external surface of a reaction cell through bombarding external surface of a reaction cell (UHV side) with an electron beam generated in UHV environment is one choice, ${ }^{22}$ the heated cell can transfer heat to the internal surface (the high pressure side) of the cell and further heating a sample installed on the high-pressure side of the cell. However, it is difficult to thermally insulate the bombarded area of the cell from the rest parts of the reaction cell; thus, a large area of or even the entire cell has to be heated, which readily induces unwanted catalytic reactions while the whole cell is heated to a relatively high temperature. One example is the formation of $\mathrm{CO}_{2}$ from $\mathrm{CO}$ oxidation (Figure 9(a)) in a reaction cell when a large area of or even the entire cell was heated, although there is no any catalyst in the reaction cell. In this new reaction cell, a direct heating with an infrared laser beam was integrated into the reaction cell. The laser beam was introduced through a flexible optic fiber installed on the homemade flange. Fiber optics exhibits quite good flexibility. In the current design, it was interfaced with a homemade flange through feedthrough of fiber optics. Figure 10 shows the integration of the laser heating to the sample stage. The laser beam has a size of 1-3 mm in diameter at the back of the sample. The laser beam diverges after it leaves the end of the optics fiber. Thus, it is necessary to remain a shorter distance between the end of the laser optics and the receiver of laser beam. The receiver is a sample holder inserted to a sample stage. A dark sample holder absorbs more energy of the laser beam. Typically, a sample holder $(8 \mathrm{~mm} \times 8 \mathrm{~mm} \times 1 \mathrm{~mm})$ made of Mo or stainless steel is fine to receive the laser beam. In all the following tests of the sample heating, a Mo plate $(8 \mathrm{~mm} \times 8 \mathrm{~mm} \times 1 \mathrm{~mm})$ was used as a sample holder to receive the laser beam.

As shown in Figure 11(a), a Mo sample in UHV can be heated to $613^{\circ} \mathrm{C}$ in $2-3 \mathrm{~min}$ by using a laser beam of $20 \mathrm{~W}$.
Without tuning up the power level, the sample temperature can remain for 21 min with a slight decay of less than $6^{\circ} \mathrm{C}$ (Figure 11(b)). This suggests that dissipation of heat from sample to any surrounding area including the reaction cell was successfully minimized. This minimization mainly results from the Macor sample stage. which well insulated the heat of high temperature sample and the low temperature cell.

\section{F. Localization of heating of sample}

Localization of heating is important for a better function of the reaction cell due to the following reasons. One is the preservation of the temperature of the reaction cell near to the room temperature since a high temperature of reaction cell can induce obvious unwanted reactions catalyzed by the internal wall of the reaction cell at $100{ }^{\circ} \mathrm{C}$ as shown in Figure 9(a). Second, a large thermal dissipation requests much more power to make a sample reach the desired temperature.

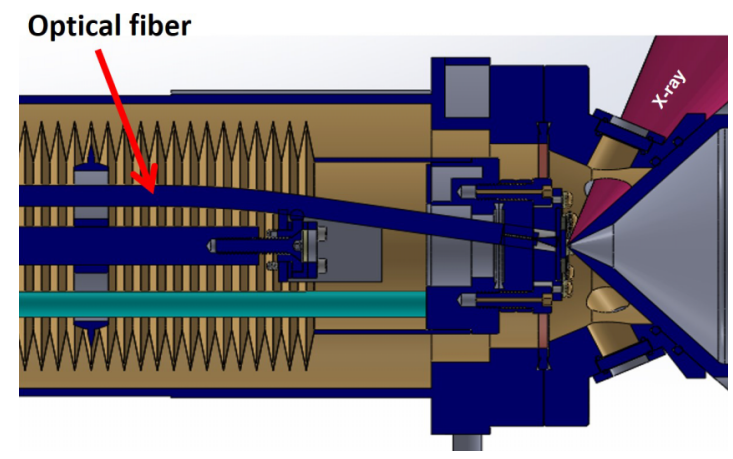

FIG. 10. Schematic showing introduction of laser beam to the back of sample holder through integration of flexible laser optics to sample stage. 


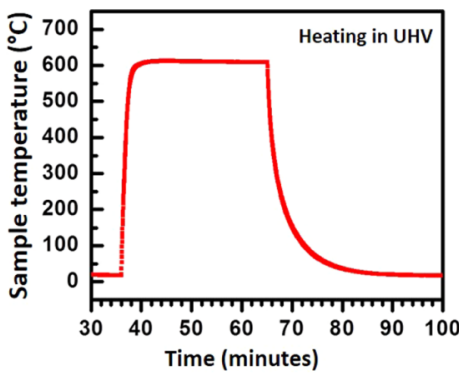

(a)

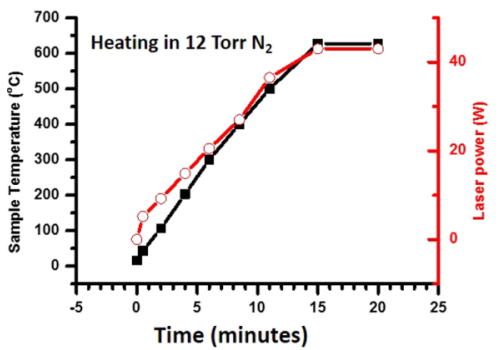

(d)

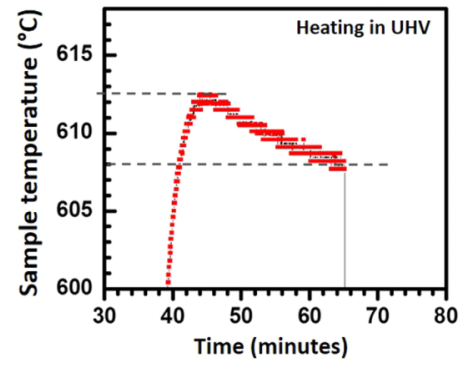

(b)

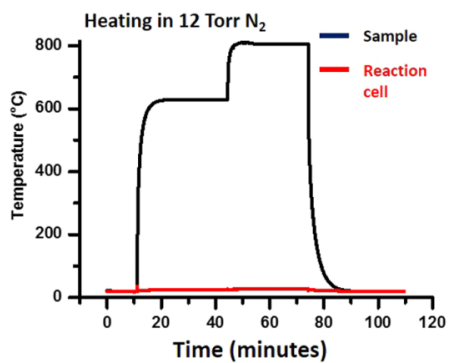

(e)

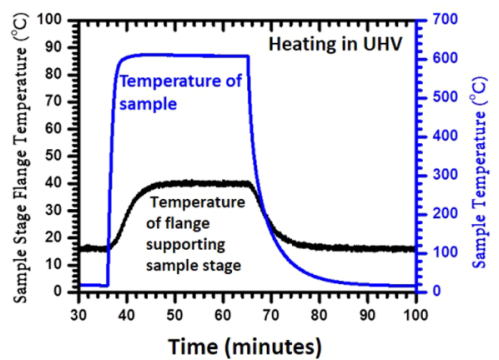

(c)

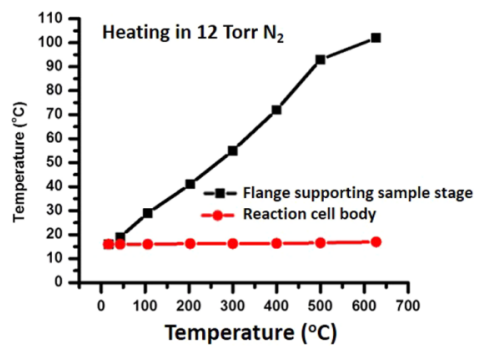

(f)

FIG. 11. Sample heating characteristic of the reaction cell. (a) Plot of the sample temperature in UHV as a function of time when 20 W of laser was turned on and remained at $20 \mathrm{~W}$ for half hour and then turned off; the sample can reach the desired temperature very quickly (in less than 5 min) and cooled to room temperature quickly. (b) Plot the temperature of sample when the power supply of the laser beam stayed at $20 \mathrm{~W}$ without any tuning up or down; within about $20 \mathrm{~min}$, the temperature of the sample only decay by $5{ }^{\circ} \mathrm{C}$. (c) Plot of both temperatures of the sample in UHV (blue curve) and the flange supporting the sample stage (which hold the sample or sample holder) (black) as a function of time when power supply of laser beam was turned to 20 W, remained at $20 \mathrm{~W}$, and turned off. (d) Sample temperature (black) and the applied laser power (red) as a function of time when the sample was heated in flowing $\mathrm{N}_{2}$ ( $4 \mathrm{ml} / \mathrm{min}, 12$ Torr of $\mathrm{N}_{2}$ ). Basically, the sample temperature increased linearly with heating laser power. (e) Plot of temperature of both the flange supporting the sample stage (black) and the reaction cell (red) as a function of sample temperature when the sample was heated in flowing $\mathrm{N}_{2}$ ( $4 \mathrm{ml} / \mathrm{min}$, 12 Torr of $\mathrm{N}_{2}$ ). Laser power used was $42 \mathrm{~W}$. (f) Evolutions of temperatures of the sample (black line) and the reaction cell (red line) when the sample was heated from room temperature to $613^{\circ} \mathrm{C}$ within 5 min and then remained at a temperature $>608{ }^{\circ} \mathrm{C}$ for about 20 min and then heated up to $800{ }^{\circ} \mathrm{C}$ within $2 \mathrm{~min}$ and then remained at a temperature $>795^{\circ} \mathrm{C}$ for $30 \mathrm{~min}$ and then cooled down to room temperature.

In other words, a ready dissipation of heat will limit the highest temperature the sample can be heated to since more power is definitely requested to heat sample and the area near to the sample stage. In addition, it will decrease the rate of cooling the sample from high temperature since the whole cell could act as a heat reservoir since much heat has been transferred to the body of a cell when a sample is heated from room temperature to a high temperature. Therefore, much more heat in the cell body has to be taken away when the sample is cooled from high temperature to room temperature. To localize the heating in terms of minimization of thermal dissipation, the sample stage was made by Macor $\left(1.5 \mathrm{~W} / \mathrm{m}{ }^{\circ} \mathrm{C}\right)$, which has a thermal conductivity lower than alumina $\left(18 \mathrm{~W} / \mathrm{m}{ }^{\circ} \mathrm{C}\right)$. In addition, keeping a short distance between the output end of the laser fiber optics and sample holder is important for minimizing the loss of laser power due to the divergence. As shown in Figure 11(c), the temperature of the flange supporting the sample stage remained $<50{ }^{\circ} \mathrm{C}$ (black line) although the temperature of sample in UHV was at $613^{\circ} \mathrm{C}$.

Figures 11(d)-11(f) plot the evolution of temperatures of the Mo sample, the flange supporting sample stage, and the reaction cell when the Mo sample was heating to $613{ }^{\circ} \mathrm{C}$ or $800{ }^{\circ} \mathrm{C}$ by the laser beam. As shown in Figure 11(d), a power of $42 \mathrm{~W}$ is needed to heat the same Mo sample to $613^{\circ} \mathrm{C}$ in flowing $\mathrm{N}_{2}$ gas at a pressure of 12 Torr with a flowing rate of $4 \mathrm{ml} / \mathrm{min}$. The temperature of the Mo sample can be remained at $>606{ }^{\circ} \mathrm{C}$ for about 30 min without tuning up the laser power (Figure 11(e)). As plotted in Figure 11(f), the temperature of the reaction cell remained at a temperature $<32^{\circ} \mathrm{C}$ (the red line), although the sample in a flowing $\mathrm{N}_{2}$ (4 ml/min) at 12 Torr was heated to $613{ }^{\circ} \mathrm{C}$; this clearly shows the dissipation of heat from the sample holder to the reaction cell is minimized definitely. It is very different from the reaction cell in which a sample is heated with ebeam. ${ }^{23}$ Meanwhile, the temperature of the flange supporting the sample stage (black line in Figure 11(f)) was remained at $108^{\circ} \mathrm{C}$ even though the sample was heated to $613^{\circ} \mathrm{C}$ (red line in Figure 11(f)). As shown in Figure 11(e), the temperature of reaction cell remained at $<40^{\circ} \mathrm{C}$ (ref line) when the Mo sample was heated to $800{ }^{\circ} \mathrm{C}$ and remained at $800^{\circ} \mathrm{C}$ in $\mathrm{N}_{2}$ gas ( $4 \mathrm{ml} / \mathrm{min}$ and 12 Torr) for about $30 \mathrm{~min}$ (black line).

\section{G. Test of function of the reaction cell}

By integrating the reaction cell to the sample manipulator, an $\mathrm{Ag}$ foil $(10 \mathrm{~mm} \times 10 \mathrm{~mm} \times 1 \mathrm{~mm})$ was assembled to a Ta sample holder and then the sample holder was installed to the sample stage in the reaction cell. As described before, the sample-aperture distance can be finely tuned through a precise linear manipulator. As shown in Figure 12, a slight change of sample-aperture distance can largely change the collection rate of photoelectrons excited from $\mathrm{Ag} 3 \mathrm{~d} 5 / 2$. The region between aperture and sample surface can be clearly observed through the video camera. In fact, the relative position between sample surface and aperture can be accurately measured on the screen 


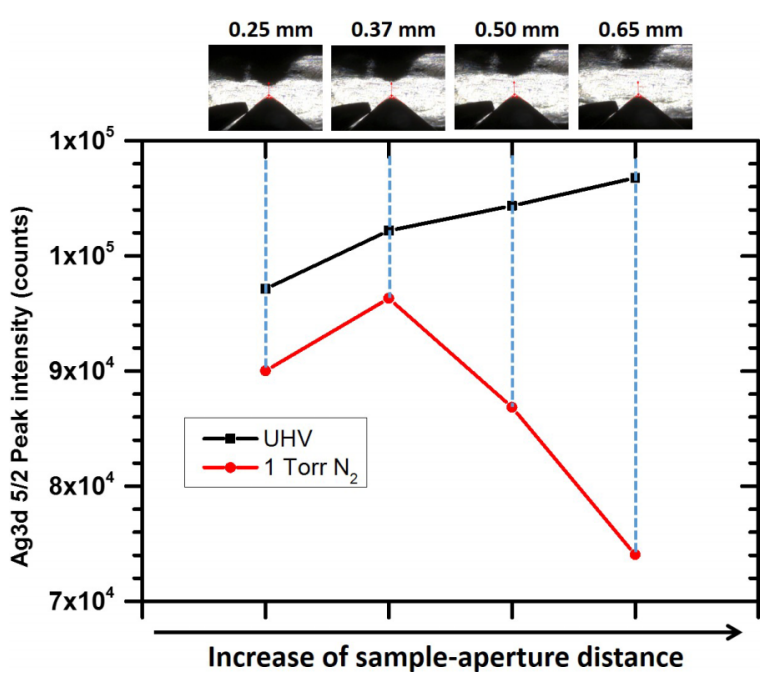

FIG. 12. Test results of Ag 3d 5/2 peak intensity as a function of sampleaperture distance in UHV and in 1 Torr $\mathrm{N}_{2}$. Slight change in sample-aperture distance can cause great fluctuation in XPS signal intensity. Analyzer slit size was $4 \mathrm{~mm} \times 30 \mathrm{~mm}$. Pass energy used was $100 \mathrm{eV}$ with standard lens mode.

since the subtle change of sample-aperture distance can be magnified largely on screen of a computer.

Figure 13 shows the $\mathrm{Ag} 3 \mathrm{~d}$ spectra in UHV at a pressure of $8 \times 10^{-10}$ Torr and in $\mathrm{N}_{2}$ at a pressure of 1 Torr and 10 Torr. Compared to the integration of $\mathrm{Ag} 3 \mathrm{~d} 5 / 2$ in UHV, $\mathrm{Ag} 3 \mathrm{~d} 5 / 2$ at 1 Torr decreases by about $10 \%$ when all the parameters of electrostatic lenses and detector remained the same. But, it significantly decreases by $93 \%$ at a pressure of 10 Torr in contrast to the intensity at UHV. Other than characterization of surface of a catalyst with AP-XPS, products and reactant in the reaction cell can be measured with a quadrupole mass spectrometer. A metal needle was installed on one of the windows of the cell neck as schematically shown in Figure 14(a). An orifice of $15 \mu \mathrm{m}$ in diameter was installed to allow leaking of gas in the reaction cell to the chamber of a mass spectrometer (Figure 14(a)). The distance between the entering port of the needle and sample surface is about $1 \mathrm{~mm}$, which allows a direct sampling of gas near to the

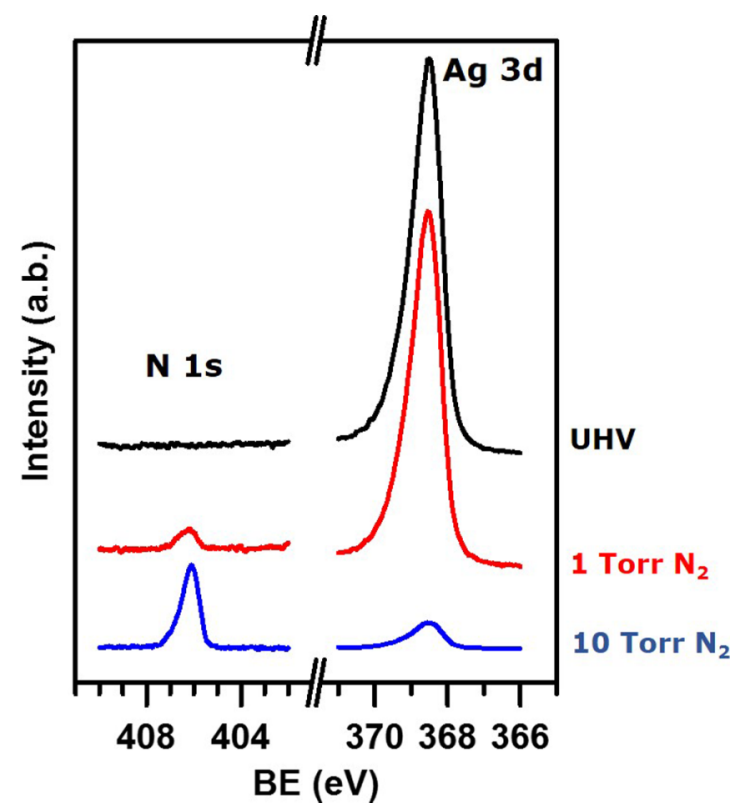

FIG. 13. In-situ XPS spectra of $\mathrm{N} 1 \mathrm{~s}$ and $\mathrm{Ag} 3 \mathrm{~d}$ in UHV, 1 Torr, and 10 Torr of $\mathrm{N}_{2}$. The sample used was a thin Ag foil.

catalyst surface (but $5 \mathrm{~mm}$ far from the aperture of front cone of the energy analyzer) to an independent chamber of the mass spectrometer. The line from the receiving needle near to sample, to an orifice, then to the chamber of the mass spectrometer is called the transportation tube here. By keeping the transportation tube warm, products with low vapor pressure can be detected. An alternative choice is to install the mass spectrometer on the first differential pumping stage $e^{23}$ by which the gas leaked through the aperture and the focal point between pre-lens pumping system and the first pumping stage will be detected. Compared to the first method shown in Figure 14, products with low vapor pressure partially or completely could condense on the wall of the pre-lens and first lens since heating the pre-lens and the first stage of lens of the energy analyzer is not allowed when the energy analyzer is collecting photoelectrons. Thus, by directly sampling gas from

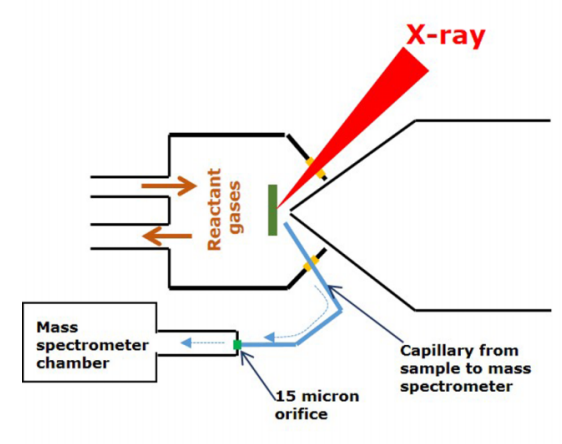

(a)

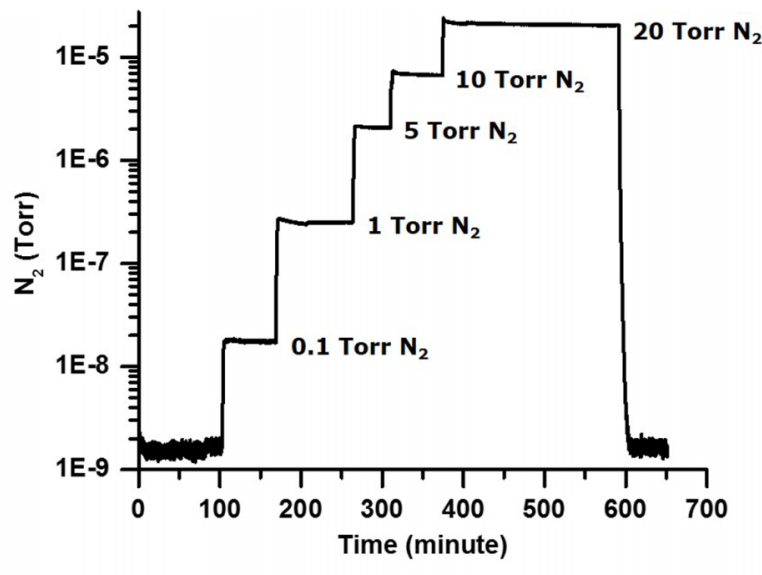

(b)

FIG. 14. (a) Diagram showing the setup for online gas products analysis. A small capillary was installed on the reaction cell. This capillary protrudes into the reaction and situates close to the sample surface. This allows the capillary to sample reaction gas product responsively into a mass spectrometer chamber for analysis with high sensitivity. In (b), an example of $\mathrm{N}_{2}$ mass spectrometer data at different $\mathrm{N}_{2}$ pressure in reaction cell. 
the region near to sample surface, the authentic composition of the gas phase near to a catalyst surface can be measured readily. As exemplified in Figure 14(b), mass spectrometer can analyze composition of a gas near to the sample surface when the sample is under any perturbations (temperature, pressure, electric potential). For instance, the gas composition can be readily analyzed when a catalyst is at any specific state (temperature or/and pressure), under photoirradiation in the case of photocatalysis or under application of electrical potential in the case of electrocatalysis. More importantly, it can track a subtle change of partial pressure of any one or more specific reactants or/and products simultaneously along a change of temperature of catalyst in the cell, a change of reaction time, molar ratio of two reactants of a catalytic reaction, electrical potential, or photoirradiation. Figure 14(b) exemplifies how the pressure of gas $\left(\mathrm{N}_{2}\right)$ in the chamber of mass spectrometer following the change of $\mathrm{N}_{2}$ pressure near to a sample in the reaction cell. With the current setup, we observed an approximately $60 \mathrm{~s}$ delay between the time when the gas inlet leak valve was open and the moment when the signal of the product was detected. By integrating the evolution of the partial pressure of reactants/product(s), a correlation between surface chemistry of the catalyst at a specific reaction or catalysis condition (or the sample or devices under a specific perturbation) and the corresponding catalytic activity and selectivity derived from data of mass spectrometer can be readily established. Such a correlation is crucial for understanding of catalytic mechanism at a molecular level toward design of new catalysts.

\section{SUMMARY}

A new flowing reaction cell was developed for ambient pressure X-ray photoelectron spectroscopy studies of a catalyst in gas phase under a reaction condition and during catalysis. The reaction cell can be conveniently assembled to the front cone through an auto-correction mechanism instead of complicated locking steps. This cell demonstrated tight sealings at the interfaces with the front cone of energy analyzer, the X-ray window of $\mathrm{Si}_{3} \mathrm{~N}_{4}$, and the access door of the sample. The base pressure of $8 \times 10^{-10}$ Torr in the UHV chamber does not increase while the pressure in the cell is increased to 10 Torr. The base pressure is only increased by $2 \times 10^{-7}$ Torr when the pressure of gas in the cell is increased to 760 Torr. Heating of a sample assembled in the cell was performed through an infrared laser beam introduced through an optic fiber and a homemade flange, which supports a fixed sample stage made of silica. With $42 \mathrm{~W}$ laser beam, a Mo sample in a flow gas of $\mathrm{N}_{2}(4 \mathrm{ml} / \mathrm{min}, 12$ Torr) can be heated to $613{ }^{\circ} \mathrm{C}$ in $5 \mathrm{~min}$. This heating is much more efficient than an approach of indirect heating through electron bombardment to the external surface of the reaction cell. Heat dissipation from a hot sample to cold reaction cell was effectively minimized through localization of heating of the sample. For instance, the temperature of the reaction cell remains at $<40^{\circ} \mathrm{C}$ when the Mo sample in $\mathrm{N}_{2}$ is heated to $800{ }^{\circ} \mathrm{C}$ in 12 Torr $\mathrm{N}_{2}$. The effective localization of heating together with coating of cell with Au thin film makes the internal surface of the reaction cell inactive for side reactions including $\mathrm{CO}$ oxidation at $100{ }^{\circ} \mathrm{C}$, although $\mathrm{CO}_{2}$ could be formed readily if $\mathrm{Au}$ thin film was not deposited to the internal surface of the reaction cell.

\section{ACKNOWLEDGMENTS}

This cell was built at University of Notre Dame. The new energy analyzer and $\mathrm{Al} \mathrm{K \alpha} \mathrm{X}$-source of this system were purchased through NSF-CHE-1462121, DE-FG0212ER1635, NSF-CBET-1264798 at Notre Dame and are now located in Tao group at University of Kansas. This work was supported by the Chemical Sciences, Geosciences and Biosciences Division, Office of Basic Energy Sciences, Office of Science, U.S. Department of Energy under Grant No. DE-SC0014561, Chemical Catalysis Program of Division of Chemistry of National Science Foundation (NSF Career Award) NSF-CHE-1462121, CBET Division of National Science Foundation NSF-CBET-1264798, King Abdullah University of Science and Technology (KAUST) Office of Sponsored Research (OSR) under Award No: OCRF2014-CRG3-62140393, Energy Frontier Research Center (Integrated Mesoscale Architectures for Sustainable Catalysis at Harvard University) funded by the US Department of Energy, Office of Science, Basic Energy Sciences under Award No. DE- SC0012573, and ARPA-REBEL program of US Department of Energy under award number DE-AR0000502.

${ }^{1}$ A. Fahlman, K. Hamrin, J. Hedman, R. Nordberg, C. Nordling, and K. Siegbahn, "Electron spectroscopy and chemical binding," Nature 210, 4 (1966).

${ }^{2} \mathrm{~N}$. Martensson and A. Nilsson, "On the origin of core-level binding energy shifts," J. Electron Spectrosc. Relat. Phenom. 75, 209-223 (1995).

${ }^{3}$ K. Siegbahn, "Electron spectroscopy for chemical analysis (ESCA)," Philos. Trans. R. Soc., A 268, 33 (1970).

${ }^{4}$ J. T. Grant and D. Briggs, Surface Analysis by Auger and X-Ray Photoelectron Spectroscopy (IM Publications, 2003).

${ }^{5} \mathrm{G}$. Ertl and H. Knozinger, Handbook of Heterogeneous Catalysis (Wiley, 2007).

${ }^{6} \mathrm{G}$. A. Somorjai and Y. Li, Introduction to Surface Chemistry and Catalysis (Wiley, 2010).

${ }^{7}$ S. Zhang, N. Luan, Y. Zhu, S. Zhan, C.-K. Tsung, and F. Tao, "In-situ studies of nanocatalysis," Acc. Chem. Res. 46, 1731-1739 (2013).

${ }^{8}$ F. Tao, S. Zhang, N. Luan, and X. Zhang, "Action of bimetallic nanocatalysts under reaction conditions and during catalysis: Evolution of chemistry from high vacuum conditions to reaction conditions," Chem. Soc. Rev. 41, 7980-7993 (2012).

${ }^{9}$ M. Salmeron and R. Schlogl, "Ambient pressure photoelectron spectroscopy: A new tool for surface science and nanotechnology," Surf. Sci. Rep. 63, 169-199 (2008).

${ }^{10} \mathrm{~F}$. Tao and M. Salmeron, "In situ studies of chemistry and structure of materials in reactive environments," Science 331, 171-174 (2011).

${ }^{11}$ Y. Tang, L. Nguyen, Y. Li, N. Wang, and F. Tao, "Surface of a catalyst in a gas phase," Curr. Opinion. Chem. Eng. 12, 52-61 (2016).

${ }^{12}$ D. F. Ogletree, H. Bluhm, G. Lebedev, C. S. Fadley, Z. Hussain, and M. Salmeron, "A differentially pumped electrostatic lens system for photoemission studies in the millibar range," Rev. Sci. Instrum. 73, 3872-3877 (2002).

${ }^{13}$ F. Mangolini, J. Ahlund, G. E. Wabiszewski, V. P. Adiga, P. Egberts, F. Streller, K. Backlund, P. G. Karlsson, B. Wannberg, and R. W. Carpick, "Angle-resolved environmental X-ray photoelectron spectroscopy: A new laboratory setup for photoemission studies at pressures up to 0.4 Torr," Rev. Sci. Instrum. 83, 093112 (2012).

${ }^{14}$ V. I. Bukhtiyarov, V. V. Kaichev, and I. P. Prosvirin, "X-ray photoelectron spectroscopy as a tool for in-situ study of the mechanisms of heterogeneous catalytic reactions," Top. Catal. 32, 3-15 (2005). 
${ }^{15}$ J. Pantforder, S. Pollmann, J. F. Zhu, D. Borgmann, R. Denecke, and H. P. Steinruck, "New setup for in situ X-ray photoelectron spectroscopy from ultrahigh vacuum to 1 mbar," Rev. Sci. Instrum. 76, 014102 (2005).

${ }^{16}$ K. Roy, C. P. Vinod, and C. S. Gopinath, "Design and performance aspects of a custom-built ambient pressure photoelectron spectrometer toward bridging the pressure gap: Oxidation of $\mathrm{Cu}, \mathrm{Ag}$, and $\mathrm{Au}$ surfaces at $1 \mathrm{mbar}_{2}$ pressure," J. Phys. Chem. C 117, 4717-4726 (2013).

${ }^{17}$ C. T. Herbschleb, P. C. van der Tuijn, S. B. Roobol, V. Navarro, J. W. Bakker, Q. Liu, D. Stoltz, M. E. Canas-Ventura, G. Verdoes, M. A. van Spronsen, M. Bergman, L. Crama, I. Taminiau, A. Ofitserov, G. J. C. van Baarle, and J. W. M. Frenken, "The ReactorSTM: Atomically resolved scanning tunneling microscopy under high-pressure, hightemperature catalytic reaction conditions," Rev. Sci. Instrum. 85, 083703 (2014).

${ }^{18}$ F. Tao, N. Luan, and S. Zhang, "Design of a new reactor-like high temperature near ambient pressure scanning tunneling microscope for catalysis studies," Rev. Sci. Instrum. 84, 034101 (2013).
${ }^{19}$ F. Tao, D. Tang, M. Salmeron, and G. A. Somorjai, "A new scanning tunneling microscope reactor used for high-pressure and high-temperature catalysis studies," Rev. Sci. Instrum. 79, 084101 (2008).

${ }^{20}$ M. J. Jackman, A. G. Thomas, and C. Muryn, "Photoelectron spectroscopy study of stoichiometric and reduced anatase $\mathrm{TiO}_{2}(101)$ surfaces: The effect of subsurface defects on water adsorption at near-ambient pressures," $\mathrm{J}$. Phys. Chem. C 119, 13682-13690 (2015).

${ }^{21}$ F. Tao and P. A. Crozier, "Atomic-scale observations of catalyst structures under reaction conditions and during catalysis," Chem. Rev. 116, 3487-3539 (2016).

${ }^{22}$ J. Schnadt, J. Knudsen, J. N. Andersen, H. Siegbahn, A. Pietzsch, F. Hennies, N. Johansson, N. Martensson, G. Ohrwall, S. Bahr, S. Maehl, and O. Schaff, "The new ambient-pressure X-ray photoelectron spectroscopy instrument at MAX-lab," J. Synchrotron Radiat. 19, 701-704 (2012).

${ }^{23} \mathrm{~F}$. Tao, "Design of an in-house ambient pressure AP-XPS using a bench-top $\mathrm{X}$-ray source and the surface chemistry of ceria under reaction conditions," Chem. Commun. 48, 3812-3814 (2012). 